\title{
How to become a neurosurgeon
}

\author{
Jacqui Wise
}

London, UK

Neurosurgery involves the assessment, diagnosis, and surgical management of disorders of the nervous system. A career in neurosurgery is demanding but very rewarding.

The first step to becoming a neurosurgeon is to complete a medical degree followed by two years of foundation training. During this time, it's important to try to get the right exposure and experience, including, if possible, getting involved in research or audit. Try to find a consultant neurosurgeon to be your mentor.

Towards the end of foundation training, applications for neurosurgical training posts can be made. In the UK this process is hosted by Yorkshire and the Humber Deanery. ${ }^{1}$

All applicants have to sit the multi-specialty recruitment assessment (MSRA) — a computer based assessment designed to test knowledge and skills as well as professional capabilities and decision making. Applications are made through Oriel online recruitment. ${ }^{2}$ Applications usually open in November with shortlisting, MSRA, and interviews occurring in the following January. Offers tend to be made in March.

\section{Stages of training}

The UK neurosurgical specialty training programme consists of eight training years from specialty trainee year 1 (ST1) to ST8. It is predominantly a "run through" specialty with no additional competitive step when a programme has been entered. Detailed information can be found on the Intercollegiate Surgical Curriculum Programme website. ${ }^{3}$

\section{Initial stage-ST1-3}

The initial stage of training allows the trainee to develop the fundamental surgical skills common to all surgical specialties as well as develop skills and competences in basic neurosurgical care, clinical neurosciences, emergency medicine; and neuro-intensive care. ST1 concentrates on core neuroscience training. The Membership of the Royal College of Surgeons examination is usually taken at the end of ST2 and must be passed before the trainee progresses to ST3. More information on the examination is available from the Royal College of Surgeons. $^{4}$

\section{Intermediate stage-ST4 and ST5 (general neurosurgical training)}

During the intermediate stage, trainees will consolidate the theoretical knowledge and clinical skills gained during the initial training stage. They will also develop competences in the following conditions: central nervous system sepsis; cranial trauma; degenerative spinal disorders; hydrocephalus; intracranial haemorrhage; neuro-oncology; spinal oncology; and spinal trauma. Online resources for neurosurgery are available through the ebrain website, ${ }^{5}$ a resource developed by the Joint Neurosciences Council.

Transition from intermediate to final neurosurgical training depends on trainees achieving the appropriate clinical and operative competences. They will need to demonstrate they can manage a wide range of emergency neurosurgical presentations and have acquired skills in microsurgery. Trainees whose clinical or professional skills are deemed unsatisfactory will be referred for targeted training and will not start the final stage.

\section{Final stage-ST6-8 (advanced neurosurgical training)}

During the final stage, trainees will spend more time in the operating theatre with proportionally less commitment to ward management and general outpatient clinics. All trainees will undertake a six month placement in a paediatric neurosurgery service under the direct supervision of paediatric neurosurgeons.

The intercollegiate examination in neurosurgery is usually taken after completing ST6. Section 1 and section 2 examinations are held twice a year. Applications should be made through the Intercollegiate Examination Board website. ${ }^{6}$

A specialist interest year can be taken flexibly during final stage training. However, trainees will only be able to start specialist interest training once their programme director is satisfied with their general neurosurgical training and their acquisition of microsurgical and advanced operative skills. Special interest training can be in the following: epilepsy surgery; functional neurosurgery; neuro-oncology; neurovascular surgery; paediatric neurosurgery; pituitary surgery; skull base surgery; or spinal surgery.

After completing training and passing the examination, the specialist advisory committee will consider whether the trainee is competent. A recommendation is made through the Joint Committee on Surgical Training to the GMC and if the trainee is deemed competent they will be given a certificate of completion of training (CCT), placed on the specialist register, and allowed to apply for a consultant post.

\section{Academic pathway}

Full time academic research or training fellowships to thesis level may be undertaken between the initial, intermediate, and final training stages or flexibly within the final stage. The 
specialist interest year will usually form part of advanced training in the trainee's academic field of interest. Academic trainees will still be expected, however, to meet all the essential competences defined in the curriculum before being awarded a CCT in neurosurgery.

\section{Certificate of eligibility for specialist registration route}

Most doctors complete a UK training programme resulting in the award of CCT. Some surgeons choose another path, however, with gradual accumulation of expertise to enable them to apply for entry on to the specialist register by the certificate of eligibility for specialist registration route. Information is available from the Joint Committee on Surgical Training.?

\section{Availability of posts}

Neurosurgery is a small surgical specialty, making up around $3 \%$ of the surgery workforce. According to NHS Digital, in
2016 there were 301 consultant neurosurgeons and 368 neurosurgical trainees on a structured training programme in England. It is a highly competitive specialty-in 2016 the competition ratio for ST1 neurosurgery was 6.50 and for ST3 neurosurgery was 3.67 . It has traditionally been a male dominated specialty but more women are choosing it as a career.

1 Health Education Yorkshire and Humber. www.yorksandhumberdeanery.nhs.uk. NHS Oriel. www.oriel.nhs.uk/Web.

Intercollegiate Surgical Curriculum Programme. www.iscp.ac.uk/curriculum/surgical/ specialty_year_syllabus.aspx.

4 Royal College of Surgeons of England. Intercollegiate MRCS. www.rcseng.ac.uk/educationand-exams/exams/search/intercollegiate-mrcs

5 ebrain. www.ebrain.net

Joint Committee on Intercollegiate Examinations. www.jcie.org.uk/Content/content.aspx. Joint Committee on Surgical Training. CESR application guidance: neurosurgery. www. jcst.org/cesr/cesr-application-guidance/neurosurgery.

Published by the BMJ Publishing Group Limited. For permission to use (where not already granted under a licence) please go to http://group.bmj.com/group/rights-licensing/ permissions 